Int. J. Dev. Biol. 50: 435-438 (2006)

doi: $10.1387 /$ ijdb.052065rs

Developmental Expression Pattern

\title{
Expression of FoxP2 during zebrafish development and in the adult brain
}

\author{
RINA SHAH ${ }^{1}$, OLGA MEDINA-MARTINEZ ${ }^{2}$, LI-FANG CHU ${ }^{3}$, RODNEY C. SAMACO ${ }^{2}$ and MILAN JAMRICH*,1,2 \\ ${ }^{1}$ Department of Molecular and Cellular Biology, ${ }^{2}$ Department of Molecular and Human Genetics and ${ }^{3}$ Cell and Molecular Biology \\ Interdepartmental Graduate Program, Baylor College of Medicine, Houston, Texas, USA
}

\begin{abstract}
Fox (forkhead) genes encode transcription factors that play important roles in the regulation of embryonic patterning as well as in tissue specific gene expression. Mutations in the human FOXP2 gene cause abnormal speech development. Here we report the structure and expression pattern of zebrafish FoxP2. In zebrafish, this gene is first expressed at the 20-somite stage in the presumptive telencephalon. At this stage there is a significant overlap of FoxP2 expression with the expression of the emxhomeobox genes. However, in contrast to emx1, FoxP2 is not expressed in the pineal gland or in the pronephric duct. After 72 hours of development, the expression of zebrafish FoxP2 becomes more complex in the brain. The developing optic tectum becomes the major area of FoxP2 expression. In the adult brain, the highest concentrations of the FoxP2 transcript can be observed in the optic tectum. In the cerebellum, only the caudal lobes show high levels of Foxp2 expression. These regions correspond to the vestibulocerebellum of mammals. Several other regions of the brain also show high levels of Foxp2 expression.
\end{abstract}

KEY WORDS: Emx, forkhead, FoxP2, homeobox, speech, telencephalon, zebrafish

Forkhead proteins are important transcriptional regulators that are involved in pattern formation during vertebrate development as well as in tissue specific gene expression and tumorogenesis (Accili and Arden, 2004, Carlsson and Mahlapuu, 2002, Dirksen and Jamrich, 1992, Dirksen and Jamrich, 1995, El-Hodiri et al., 2001, Erickson, 2001, Kaufmann and Knochel, 1996, Lai et al., 2001, Lai et al., 1990, Lehmann et al., 2003, Li and Vogt, 1993, Tseng et al., 2004).

FOXP2, a member of the Foxpsubfamily of Fox genes, is the only gene shown to be involved in speech and language development in humans (Bruce and Margolis, 2002, Enard et al., 2002, Fisher et al., 1998, Katoh, 2004, Lai et al., 2001, Lu et al., 2002, Saleem et al., 2003, Shu et al., 2001, Wang et al., 2003, Zhang et al., 2002). Mutations in this gene result in impaired linguistic and grammatical skills that, together with diminished control of complex face and mouth movements, lead to disrupted speech (Hurst et al., 1990, Vargha-Khadem et al., 1998). A recent study showed expression of FoxP2 in the entire adult brain of birds and crocodiles (Haesler et al., 2004). In this paper, we provide information about the isolation, sequence and expression pattern of zebrafish FoxP2 during development and in adult brain.

Foxp2 is somewhat of an unusual protein in that it contains a forkhead and zinc finger domain. PCR and degenerate primers were used to isolate a cDNA fragment of the zebrafish FoxP2gene that encodes both of these domains of the protein. After sequencing the isolated PCR fragment, we found that our sequence has a high homology to several zebrafish EST fragments in the GenBank database. Figure 1 shows the comparison of the deduced amino acid sequence of the zebrafish to the mouse and human FOXP2 protein. This comparison shows that the FoxP2 protein is highly conserved during evolution. Not surprisingly, the similarities between the zebrafish, mouse and human FOXP2 protein are highest in the forkhead and the zinc finger domain. However, the overall conservation of amino acids in the entire protein between zebrafish and human is unusually high, greater than $80 \%$. The most notable difference between these three proteins is in the poly-glutamine region. While the human and mouse FOXP2 contain as many as 50 glutamines in two adjacent poly-glutamine regions, the zebrafish FoxP2 contains only nine. The functional significance of this difference is not known, but the expansion of poly-glutamine stretches of proteins has been identified as the cause of several neurodegenerative diseases in humans (for review see (La

Abbreviations used in this paper: EST, expressed sequence tag; PCR, polymerase chain reaction.

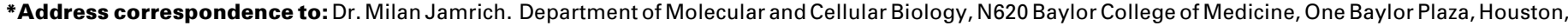
Texas 77030, USA. Fax: +1-713-798-3017. e-mail: jamrich@bcm.tmc.edu
} 
Spada and Taylor, 2003).

\section{Expression of FoxP2 during embryogenesis}

Expression of FoxP2 begins in zebrafish at 20-somites in the dorsal telencephalon (Fig. 2A, C). When we compared the FoxP2 expression pattern to the expression pattern of other genes transcribed at this stage, we found that FoxP2expression is very similar to the expression pattern of the emx homeobox genes (Kawahara and Dawid, 2002, Morita et al., 1995). However, in contrast to emx1 (Kawahara and Dawid, 2002), FoxP2 does not show expression in the pineal gland, in pronephric duct and the urogenital opening (Fig. 2B). The expression of FoxP2 in the dorsal telencephalon is partially overlapping with that of $e m \times 1$. A double in situhybridization demonstrates that $e m \times 1$ expression at the 20-somite stage is limited to a subdomain of Foxp2expression (Fig. 2D). Expression of Foxp2 becomes more complex in the brain after 48 hours of development. At 7 days post fertilization, there is expression of FoxP2 in several domains throughout the entire brain (Fig. 3A). The highest levels of FoxP2expression can be observed in the presumptive optic tectum.
zFOXP2 MMQESANETISNSSMSQNGMSSLSSQLDAGSRDGRSSGETSSEVSAVELLHLQQQQALQA mFOxp2 MMQESVTETISNSSMNQNGMSTLSSQLDAGSRDGRSSGDTSSEVSTVELLHLQQQQALQA hFOXP2 MMQESATETISNSSMNQNGMSTLSSQLDAGSRDGRSSGDTSSEVSTVELLHLQQQQALQA 61

zFOxP2 ARQLLLQQPGSGLKSPKNNDKORPLQVPVSVAMMS PQVITPQQMQQILQQQVLSPQQLQA mFoxp2 ARQLLLQQQT SGLKSPKSSEKQRPLQVPVSVAMMT PQVITPQQM Q ILQQQVLSPQQLQA hFOXP2 ARQLLLQQQTSGLKSPKSS DKQRPLQVPVSVAMMT PQVITPQQMQQILQQQVLSPQQLQA 121

zFOXP2 LLQQQQAVMLQQQHLQEFYKKQQEQLHLQLLQQQ-

mFOXP2 LLQQQQAVMLQQQQLQEFYKKQQEQLHLQLLQQQ $Q Q Q Q Q Q Q Q Q Q Q Q Q Q Q Q Q Q Q Q Q Q Q Q Q Q Q Q Q Q Q$ hFOXP2 LLQQQQAVMLQQQQLQEFYKKQQEQLHLQLLQQQQQQQQQQQQQQQQQQQQQQQQQQQQQQQ 181

zFOxP2 ----------HPGKQAKEQQQQQQ----LAAQQLVFQQQLLQMQQLQQQQHLLNMQRQG mFoxp2 QQQQQQQQQQQHPGKQAKEQQQQQQQQQ-LAAQQLVFQQQLLQMQQLQQQQHLLSLQRQG

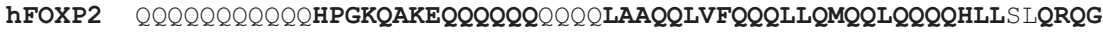
241

zFOXP2 LLSMPPGPGQPTLPGQTLPPAGLSPAELQQLWKDVTASHTMEDNGMKHSGLDLSTNNNTS mFoxp2 LISIPPG--QAALPVQSLPQAGLSPAE IQQLWKEVTGVHSMEDNGI KHGGLDLTTNNSSS hFOXP2 LISIPPG--QAALPVQSLPQAGLSPAE IQQLWKEVTGVHSMEDNG I KHGGLDLTTNNSSS

301

Zinc Finger

zFOXP2 TTSTSNPKASPPITHHSMSNGQSPALNNRRESSLHEETAVSHSLYGHGVCKWPGCESICD mFOXP2 TTSSTTSKASPPITHHS IVNGQS SVLNARRDSS SHEETGASHTLYGHGVCKWPGCESICE hFOXP2 TTSSNTSKASPPITHHS IVNGQS SVLSARRDSS SHEET GASHTLYGHGVCKWPGCESICE 361

zFOXP2 DFGQFLKHLNNEHALDDRSTAQCRVQMQVVQQLEIQLSKERERLQAMMAHLHMRPSEPKP mFoxp2 DFGQFLKHLNNEHALDDRSTAQCRVQMQVVQQLEIQLSKERERLQAMMTHLHMRPSEPKP hFOXP2 DFGQFLKHLNNEHALDDRSTAQCRVQMQVVQQLEIQLSKERERLQAMMTHLHMRPSEPKP 421

zFOXP2 SPKPLNLVSSVTMSKNLPS ISPPNLPOTPTTPTAPVTPLSOMPOVPNVLSPANVPSMGAM mFoxp2 SPKPLNLVSSVTMSKNMLETSPQSLPQTPTTPTAPVTPITQGP---SVITPASVPNVGAI hFOXP2 SPKPLNLVSSVTMSKNMLETSPQSLPQTPTTPTAPVTPITQGP---SVITPASVPNVGAI 481

ZFOXP2 RRRHTDKYSMALSSEIAPNYEFYKNADVRPPFTYATLIRQAIMESSDRQLTLNEIYSWFT mFOXP2 RRRHSDKYNIPMSSEIAPNYEFYKNADVRPPFTYATLIRQAIMESSDRQLTLNEIYSWFT hFOXP2 RRRHSDKYNIPMSSEIAPNYEFYKNADVRPPFTYATLIRQAIMESSDRQLTLNEIYSWFT

\section{$541 \quad$ Forkhead domain}

zFOXP2 RTFAYFRRNAATWKNAVRHNLSLHKCFVRVENVKGAVWTVDEMEYQKRRSQKITGSPTLV mFOXP2 RTFAYFRRSAATWKNAVRHNLSLHKCFVRVENVKGAVWTVDEVEYQKRRSQKITGSPTLV hFOXP2 RTFAYFRRNAATWKNAVRHNLSLHKCFVRVENVKGAVWTVDEVEYQKRRSQKITGSPTLV 601

zFOXP2 KNLPSSLGYGAALNASLQAALAETTLPLLGNPGLMNSASAMMGASP PVMMSGSPTGLLQG mFoxp2 KNIPT SLGYGAALNASLQAALAES SLPLLSNPGL INNAS------------ SGLLQA hFOXP2 KNIPTSLGYGAALNASLQAALAESSLPLLSNPGL INNAS------------SGLLQA $\overline{661}$

zFOXP2 TTHEELNGTLDHLDTNGHSSPGYS--PHTHLPPIHVKEEPLNMEDEDCPMSLVTTANHSP mFoxp2 V-HEDLNGSLDHIDSNGNSSPGCSPQPHIHS--IHVKEEPVIAEDEDCPMSLVTTANHSP hFOXP2 V-HEDLNGSLDHIDSNGNSSPGCSPQPHIHS--IHVKEEPVIAEDEDCPMSLVTTANHSP 721

zFOXP2 ELDDDRELEEGNLSEDLE

mFOXP2 ELEDDREIEEEPLSEDLE

hFOXP2 ELEDDREIEEEPLSEDLE

Fig. 1. Amino acid sequence comparison between zebrafish FoxP2 protein and its orthologues in mouse and human. Identical amino acids are in bold. The absence of residues at the corresponding region is indicated by dashes. The zinc finger and the forkhead domain are underlined.

\section{Expression of FoxP2 in the adult brain}

In the adult brain, the periventicular gray zone of the optic tectum shows very high levels of FoxP2 expression (Fig. 3B, D and E). However, specific regions in the ventral forebrain and the hypothalamus display high levels of FoxP2transcripts as well. The ventral telencephalon (Fig. $3 \mathrm{~B}$, most anterior expression domain) and the preoptic area show high levels of FoxP2 transcripts (Fig. 3B, C). There is strong expression in the periventricular pretectum and weaker expression in the dorsal thalamus and ventral posterior tuberculum (Fig. 3D). The rostral cerebellum does not express this gene (Fig. 3E, F), while the caudal lobe of cerebellum does (Fig. 3G). The caudal lobe of cerebellum corresponds to the vestibulocerebellum of mammals. The cerebellar FoxP2 expression is in a conspicuous band of seemingly large cells, possibly corresponding to Purkinje cells. Specific cells in the superior reticular nucleus show distinct expression of FoxP2, as do some cells in the medial octavolateralis nucleus, which is the primary sensory nucleus for the lateral line (Mueller et al., 2004).

The functional significance of the temporospatial expression of FoxP2 in zebrafish neural tissue and for that matter in other species, is yet to be elucidated. There is a great shift of expression between the initial expression of FoxP2 in the dorsal telencephalon and the widespread, but region-specific expression in the adult brain. The significance of this shift is not understood, but it is likely that FoXP2 plays a different role during the early development of the brain than it does later in the differentiated neuronal cells. If the expression of FoXP2 is any indication of its sites of function, then FoxP2is clearly involved in several aspects of brain development and function unrelated to language formation. There are many simmilarities of FoxP2 expression in the brains of birds and crocodiles (Haesler et al., 2004) when compared to that of zebrafish, e.g., ventral telencephalon (possibly striatum), optic tectum, torus semicircularis/inferior colliculus, cerebellum, dorsal thalamus and hypothalamus. It is the challenge for the future to determine the significance of FoxP2expression in the different 
A

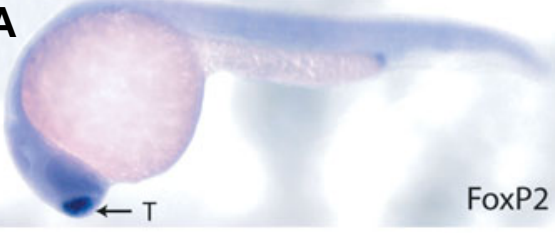

B

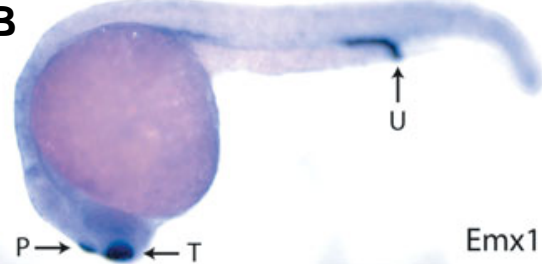

C

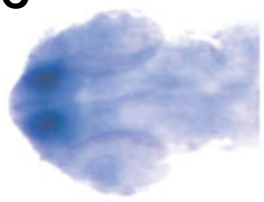

FoxP2
D

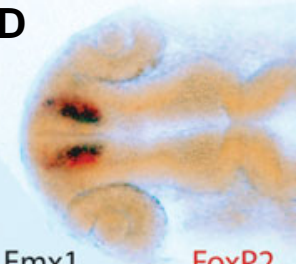

Emx1
A

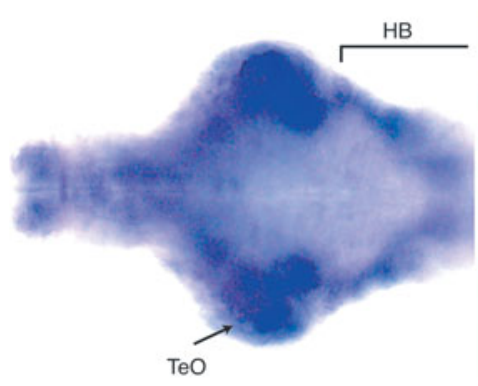

B

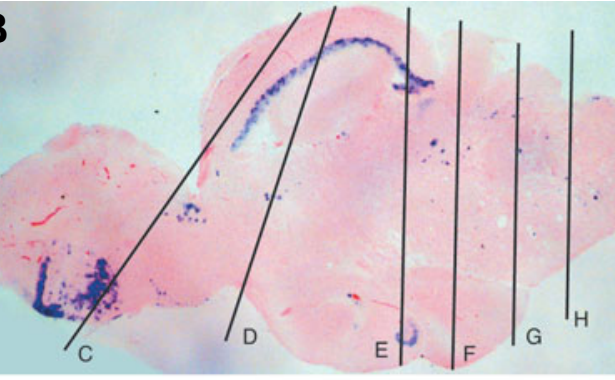

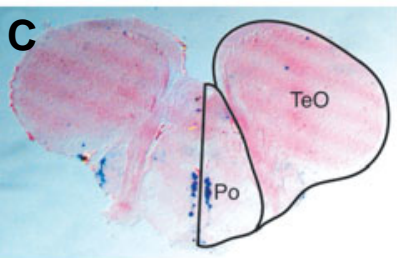
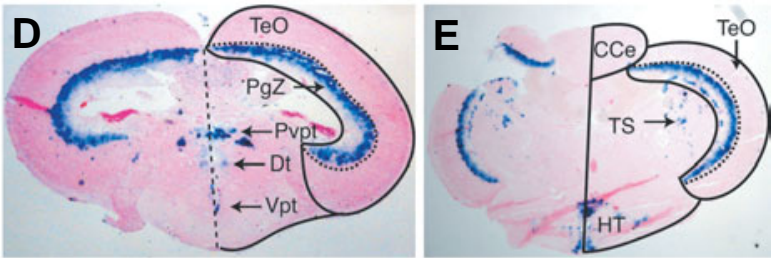

$\mathbf{F}$

G

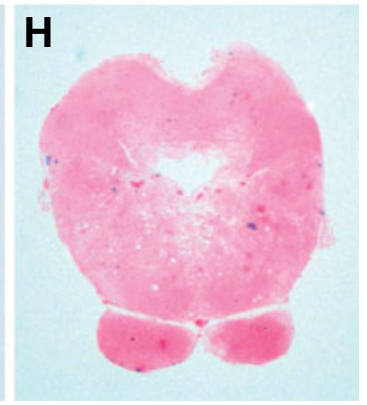

Fig. 2. (Left) Expression of FoxP2 during zebrafish embryogenesis. (A) Lateral view of in situ hybridization of FoxP2 probe to a 20somite zebrafish embryo. The expression is in the dorsal telencephalon (arrow). (B) Lateral view of in situ hybridization of Emx1 probe to a 20-somite zebrafish embryo. Expression is in the dorsal telencephalon (T), pineal gland (P) and the urogenital opening (U). (C) Dorsal view of the head region from a 20-somite zebrafish embryo hybridized with a FoxP2 probe. (D) Double in situ hybridization of a FoxP2 probe (red) and Emx1 (black) to the head region of a 20-somite zebrafish embryo. Dorsal view.

Fig. 3. (Right) Expression of FoxP2 in the zebrafish brain. (A) Dorsal view of in situ hybridization of FoxP2 probe to the isolated brain from a 7 dayold zebrafish. The isolated brain was opened along its dorsal axis and flattened. Anterior is to the left. (B) Sagittal section of a brain from a 3 months old zebrafish hybridized with a FoxP2 probe. Vertical lines indicate the positions of cross sections in images (C- $\mathrm{H})$. Cross sections, hybridized with a FoxP2 probe, through the (C) telencephalon, (D)optic tectum, (E) optic tectum, cerebellum and hypothalamus, (F) cerebellum, (G) caudal lobe of the cerebellum and the medulla oblongata. Arrow in (F) indicates the expression in the superior reticular formation. Arrow in (G) indicates expression in the medial octavolateralis nucleus. (H) A section caudal to (G) shows no expression of FoxP2. Abbreviations: Cc, cerebellar crest; CaC, caudal lobe of cerebellum; CCe, corpus cerebelli; DIL, diffuse nucleus of the inferior hypothalamic lobe; Dt, dorsal thalamus; HB, hindbrain; HT, hypothalamus; MO, medulla oblongata; MoN, medial octavolateralis nucleus; PgZ, periventicular grayzone of the optic tectum; Po, preoptic area; Pvpt, periventricular pretectum; SRN, superior reticular nucleus; TeO, optic tectum; TS, torus semicircularis; Vpt, ventral posterior tuberculum.

brain areas.

While this manuscript was under review, a paper by (Bonkowsky and Chien, 2005) described expression of FoxP2 during early stages of zebrafish development. These authors have demonstrated that there is a widespread expression of FoxP2 in the neural system of zebrafish during the first three days of development.

\section{Experimental Procedures}

\section{Isolation of zebrafish FoxP2}

We used PCR and degenerate primers to isolate a CDNA fragment of the FoXP2gene encoding the forkhead and the zinc finger domain. The PCR reaction was carried out on reverse transcribed cDNA generated from 9-16 day old zebrafish embryos according to manufacturer's instructions. Degenerate primers encoding the following peptides were used: FoxP2-F: HGVCKW; FoxP2-R: -HKCFVRV

After sequencing the isolated PCR fragment, we found several EST fragments with high homology in the GenBank database (BQ617568; BQ783717).

\section{Whole mount in situ hybridization and histology}

Whole mount in situ hybridization was performed according to (Harland, 1991). For double in situ hybridization we followed the protocol of (Hauptmann and Gerster, 1994). For sections, the zebrafish brain was embedded in paraffin and 7 micrometers sections were made for in situ hybridization. Sections were dewaxed in xylene, rehydrated and hybridized with a digoxigeninlabeled probe. After the chromogenic reaction, the sections were 
counterstained with hematoxylin and eosin.

\section{Acknowledgements \\ We would like to thank Dr. Mario Wullimann with help in the localization of FoxP2 expression in the adult brain and Dr. Eric Swindell for a critical reading of this manuscript.}

\section{References}

ACCILI, D. and ARDEN, K.C. (2004). Foxos at the crossroads of cellular metabolism, differentiation and transformation. Ce//117: 421-6.

BONKOWSKY, J.L. and CHIEN, C.B. (2005). Molecular cloning and developmental expression of foxp2 in zebrafish. Dev Dyn.

BRUCE, H.A. and MARGOLIS, R.L. (2002). Foxp2: Novel exons, splice variants and cag repeat length stability. Human Genetics 111: 136-44.

CARLSSON, P. and MAHLAPUU, M. (2002). Forkhead transcription factors: Key players in development and metabolism. Dev Bio/250: 1.

DIRKSEN, M.L. and JAMRICH, M. (1992). A novel, activin-inducible, blastopore lipspecific gene of xenopus laevis contains a fork head DNA-binding domain. Genes Dev. 6: 599-608.

DIRKSEN, M.L. and JAMRICH, M. (1995). Differential expression of fork head genes during early xenopus and zebrafish development. Dev Genet17: 107-16.

EL-HODIRI, H., BHATIA-DEY, N., KENYON, K., AULT, K., DIRKSEN, M. and JAMRICH, M. (2001). Fox (forkhead) genes are involved in the dorso-ventral patterning of the xenopus mesoderm. Int J Dev Bio/45: 265-71.

ENARD, W., PRZEWORSKI, M., FISHER, S.E., LAI, C.S., WIEBE, V., KITANO, T., MONACO, A.P. and PAABO, S. (2002). Molecular evolution of foxp2, a gene involved in speech and language. Nature 418: 869-72.

ERICKSON, R.P. (2001). Forkhead genes and human disease. J App/ Genet 42 211-21

FISHER, S.E., VARGHA-KHADEM, F., WATKINS, K.E., MONACO, A.P. and PEMBREY, M.E. (1998). Localisation of a gene implicated in a severe speech and language disorder. Nat Genet 18: 168-70.

HAESLER, S., WADA, K., NSHDEJAN, A., MORRISEY, E.E., LINTS, T., JARVIS, E.D. and SCHARFF, C. (2004). Foxp2 expression in avian vocal learners and non-learners. J Neurosci24: 3164-75.

HARLAND, R.M. (1991). In situ hybridization: An improved whole-mount method for xenopus embryos. Methods Cell Bio/36: 685-95.

HAUPTMANN, G. and GERSTER, T. (1994). Two-color whole-mount in situ hybridization to vertebrate and Drosophila embryos. Trends Genet 10: 266.

HURST, J.A., BARAITSER, M., AUGER, E., GRAHAM, F. and NORELL, S. (1990). An extended family with a dominantly inherited speech disorder. Dev Med Child Neuro/32: 352-5

KATOH, M. (2004). Human fox gene family (review). Int J Onco/25: 1495-500.

KAUFMANN, E. and KNOCHEL, W. (1996). Five years on the wings of fork head. Mech Dev 57: 3-20.

KAWAHARA, A. and DAWID, I.B. (2002). Developmental expression of zebrafish emx1 during early embryogenesis. Gene Expr Patterns 2: 201-6.

LA SPADA, A.R. and TAYLOR, J.P. (2003). Polyglutamines placed into context. Neuron 38: 681-4.

LAI, C.S., FISHER, S.E., HURST, J.A., VARGHA-KHADEM, F. and MONACO, A.P (2001). A forkhead-domain gene is mutated in a severe speech and language disorder. Nature 413: 519-23.

LAI, E., PREZIOSO, V.R., SMITH, E., LITVIN, O., COSTA, R.H. and DARNELL, J.E., JR. (1990). Hnf-3a, a hepatocyte-enriched transcription factor of nove structure is regulated transcriptionally. Genes Dev 4: 1427-36.

LEHMANN, O.J., SOWDEN, J.C., CARLSSON, P., JORDAN, T. and BHATTACHARYA, S.S. (2003). Fox's in development and disease. Trends Genet. 19: 339-44.

LI, J. and VOGT, P.K. (1993). The retroviral oncogene qin belongs to the transcription factor family that includes the homeotic gene fork head. Proc Nat/ Acad Sci USA 90: 4490-4.

LU, M.M., LI, S., YANG, H. and MORRISEY, E.E. (2002). Foxp4: A novel member of the foxp subfamily of winged-helix genes co-expressed with foxp1 and foxp2 in pulmonary and gut tissues. Gene Expression Patterns 2: 223-8.

MORITA, T., NITTA, H., KIYAMA, Y., MORI, H. and MISHINA, M. (1995). Differential expression of two zebrafish emx homeoprotein mrnas in the developing brain. Neurosci Lett 198: 131-4.

MUELLER, T., VERNIER, P. and WULLIMANN, M.F. (2004). The adult central nervous cholinergic system of a neurogenetic model animal, the zebrafish danio rerio. Brain Res 1011: 156-69.

SALEEM, R.A., BANERJEE-BASU, S., BERRY, F.B., BAXEVANIS, A.D. and WALTER, M.A. (2003). Structural and functional analyses of disease-causing missense mutations in the forkhead domain of foxc1. Hum Mo/Genet 12: 29933005

SHU, W., YANG, H., ZHANG, L., LU, M.M. and MORRISEY, E.E. (2001). Characterization of a new subfamily of winged-helix/forkhead (fox) genes that are expressed in the lung and act as transcriptional repressors. J Bio/ Chem 276 27488-97.

TSENG, H.T., SHAH, R. and JAMRICH, M. (2004). Function and regulation of foxf1 during xenopus gut development. Development 131: 3637-47.

VARGHA-KHADEM, F., WATKINS, K.E., PRICE, C.J., ASHBURNER, J., ALCOCK, K.J., CONNELLY, A., FRACKOWIAK, R.S., FRISTON, K.J., PEMBREY, M.E. MISHKIN, M. et al. (1998). Neural basis of an inherited speech and language disorder. Proc Natl Acad Sci USA 95: 12695-700.

WANG, B., LIN, D., LI, C. and TUCKER, P. (2003). Multiple domains define the expression and regulatory properties of foxp 1 forkhead transcriptional repres sors. J. Biol. Chem. 278: 24259-68.

ZHANG, J., WEBB, D.M. and PODLAHA, O. (2002). Accelerated protein evolution and origins of human-specific features: Foxp2 as an example. Genetics 162 1825-35.

Received: August 2005

Reviewed by Referees: September 2005

Modified by Authors and Accepted for Publication: November 2005 